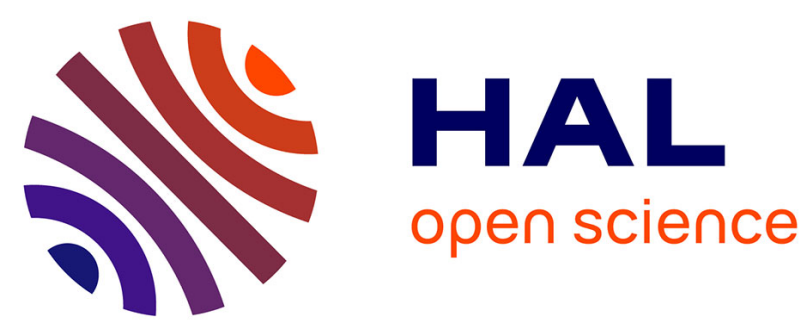

\title{
Magnetic and photomagnetic studies in nanocrystalline $\mathrm{Ni0.5Zn0.5Fe1.7Co0.3O4}$
}

Dhirendra Bahadur, Cédric Desplanches, S. Rajakumar, Jean-François Létard

\section{To cite this version:}

Dhirendra Bahadur, Cédric Desplanches, S. Rajakumar, Jean-François Létard. Magnetic and photomagnetic studies in nanocrystalline Ni0.5Zn0.5Fe1.7Co0.3O4. Journal of Applied Physics, 2008, 103 (7), pp.07B724. 10.1063/1.2831389 . hal-00258982

\section{HAL Id: hal-00258982 \\ https://hal.science/hal-00258982}

Submitted on 3 Nov 2021

HAL is a multi-disciplinary open access archive for the deposit and dissemination of scientific research documents, whether they are published or not. The documents may come from teaching and research institutions in France or abroad, or from public or private research centers.
L'archive ouverte pluridisciplinaire HAL, est destinée au dépôt et à la diffusion de documents scientifiques de niveau recherche, publiés ou non, émanant des établissements d'enseignement et de recherche français ou étrangers, des laboratoires publics ou privés. 


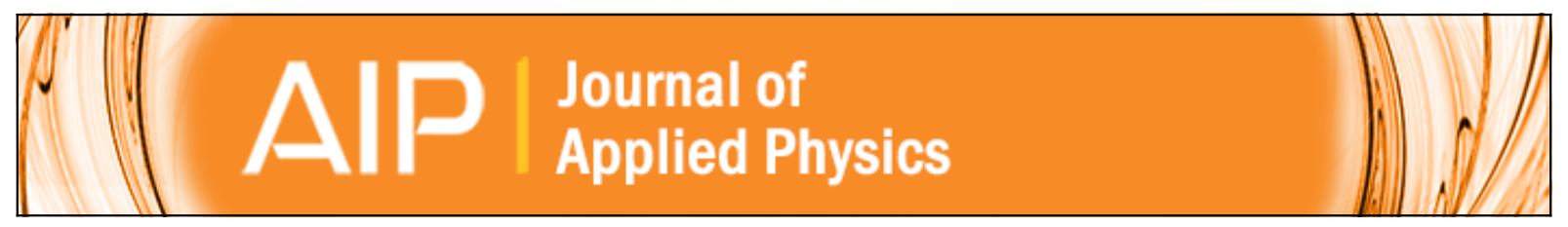

Magnetic and photomagnetic studies in nanocrystalline Ni 0.5 Zn 0.5 Fe 1.7 Co 0.3 O 4

D. Bahadur, C. Desplanches, S. Rajakumar, and J.-F. Létard

Citation: Journal of Applied Physics 103, $07 B 724$ (2008); doi: 10.1063/1.2831389

View online: http://dx.doi.org/10.1063/1.2831389

View Table of Contents: http://scitation.aip.org/content/aip/journal/jap/103/7?ver=pdfcov

Published by the AIP Publishing

\section{Articles you may be interested in}

Spin glasslike behavior and magnetic enhancement in nanosized $\mathrm{Ni}-\mathrm{Zn}$ ferrite system

J. Appl. Phys. 108, 034307 (2010); 10.1063/1.3456174

Room temperature ferromagnetic ordering in indium substituted nano-nickel-zinc ferrite

J. Appl. Phys. 105, 07A521 (2009); 10.1063/1.3062956

Photoemission and $\mathrm{x}$-ray absorption studies of valence states in ( $\mathrm{Ni}, \mathrm{Zn}, \mathrm{Fe}, \mathrm{Ti}$ ) $3 \mathrm{O} 4$ thin films exhibiting photoinduced magnetization

Appl. Phys. Lett. 92, 082502 (2008); 10.1063/1.2885080

Structural and magnetic properties of NiZn and $\mathrm{Zn}$ ferrite thin films obtained by laser ablation deposition J. Appl. Phys. 97, 10G105 (2005); 10.1063/1.1854416

High-temperature cluster glass state and photomagnetism in $\mathrm{Zn}$ - and Ti-substituted NiFe $2 \mathrm{O} 4$ films J. Appl. Phys. 97, 083541 (2005); 10.1063/1.1863422

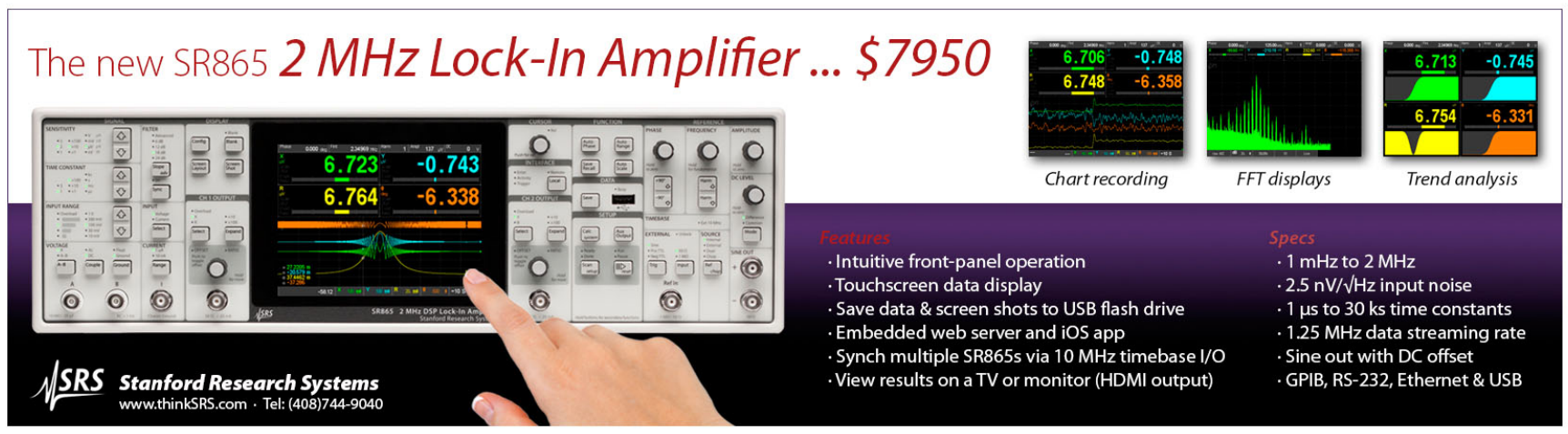




\title{
Magnetic and photomagnetic studies in nanocrystalline $\mathrm{Ni}_{0.5} \mathrm{Zn}_{0.5} \mathrm{Fe}_{1.7} \mathrm{Co}_{0.3} \mathrm{O}_{4}$
}

\author{
D. Bahadur, ${ }^{1, a)}$ C. Desplanches, ${ }^{2}$ S. Rajakumar, ${ }^{1}$ and J.-F. Létard ${ }^{2, b)}$ \\ ${ }^{1}$ Department of Metallurgical Engineering and Materials Science, Indian Institute of Technology, Bombay, \\ Powai, Mumbai 400076, India \\ ${ }^{2}$ ICMCB, CNRS, Université Bordeaux 1, 87 Avenue du Dr A. Schweitzer, 33608 Pessac Cedex, France
}

(Presented on 6 November 2007; received 3 October 2007; accepted 19 October 2007; published online 19 February 2008)

This work presents magnetic and photomagnetic studies on the nanocrystalline form of the spinel $\mathrm{Ni}_{0.5} \mathrm{Zn}_{0.5} \mathrm{Fe}_{1.7} \mathrm{Co}_{0.3} \mathrm{O}_{4}$. Field cooled, zero field cooled, and hysteresis have been recorded for this compound with and without irradiation. Kinetics of relaxation of the magnetization in the dark and after irradiation has also been studied. An explanation of these results is given in the framework of freezing/melting of cluster glass behavior. (C) 2008 American Institute of Physics. [DOI: 10.1063/1.2831389]

\section{INTRODUCTION}

The photoinduced magnetic studies in magnetic oxides, such as manganites, cobaltites, diluted magnetic semiconductors, and ferrites, have gained great importance in recent past. ${ }^{1,2}$ Seki et al. ${ }^{3}$ have investigated the photomagnetic response of the thin films of $\mathrm{Zn}$ - and Ti-substituted $\mathrm{NiFe}_{2} \mathrm{O}_{4}$, and $\mathrm{Al}$-substituted $\mathrm{Fe}_{3} \mathrm{O}_{4}$, and the results have been interpreted in terms of a photoinduced intervalence charge transfer (IVCT) between the ions. Muraoka et al. have investigated the effect of light irradiation on $\mathrm{Zn}_{0.5} \mathrm{Co}_{0.5} \mathrm{Fe}_{2} \mathrm{O}_{4}{ }^{4}$ $\mathrm{Mg}_{1.4} \mathrm{Fe}_{1.2} \mathrm{Ti}_{0.4} \mathrm{O}_{4}{ }^{5}$ ferrite thin films and discussed the results on the basis of spin glass state.

The present work deals with the magnetic and photomagnetic investigations on the compound $\mathrm{Ni}_{0.5} \mathrm{Zn}_{0.5} \mathrm{Fe}_{1.7} \mathrm{Co}_{0.3} \mathrm{O}_{4}$ in nanocrystalline form. The base compound $\mathrm{Ni}_{1-x} \mathrm{Zn}_{x} \mathrm{Fe}_{2} \mathrm{O}_{4}$ is well known for its soft magnetic properties. It may be noted that $\mathrm{Zn}^{2+}$ and $\mathrm{Ni}^{2+}$ ions in the spinel structure have a very strong preference for tetrahedral and octahedral sites, respectively. $\mathrm{Fe}^{3+}$ ions do not exhibit any strong preference for either the tetrahedral $A$ or the octahedral $B$ sites. Co is likely to be there in the structure in either $\mathrm{Co}^{2+}$ or $\mathrm{Co}^{3+}$, both of which have a strong preference for octahedral site. These preferences, however, may significantly change in the nanocrystalline form. An additional degree of freedom with cobalt ion is the possibility of variable spin states, besides the variable valency. The systems which possess multivalent ions at the equivalent energy sites as in the present case may undergo charge transfer phenomena by light irradiation. For the present compound, both the cobalt $\left(\mathrm{Co}^{2+}\right.$ and $\left.\mathrm{Co}^{3+}\right)$ and iron $\left(\mathrm{Fe}^{2+}\right.$ and $\left.\mathrm{Fe}^{3+}\right)$ ions may exist at the octahedral site and can easily undergo charge transfer due to their abilities to exist in variable valence states. Nickel is also known to exist in $2+$ and $3+$ states particularly in relation to charge transfer in ferrites. This eventually may impart different properties on light irradiation, such as reported on molecular-based materials. ${ }^{6}$

\footnotetext{
a) Tel.: +91-22-25767632. Electronic mail: dhirenb@iitb.ac.in

${ }^{b)}$ Electronic mail: letard@icmcb-bordeaux.cnrs.fr.
}

\section{EXPERIMENTAL SECTION}

For the synthesis of $\mathrm{Ni}_{0.5} \mathrm{Zn}_{0.5} \mathrm{Fe}_{1.7} \mathrm{Co}_{0.3} \mathrm{O}_{4}$, the stoichiometric proportion of metal nitrates are dissolved in distilled water. Citric acid as a fuel was added, the metal nitrates to citrates ratio and $\mathrm{pH}$ of the solution were maintained at $1: 1$ and 7 respectively. After slow dehydration of the nitrate-fuel complexes, the temperature was raised to $150{ }^{\circ} \mathrm{C}$. The gel got autoignited and dry foam formed, which is ground and heat treated at $850{ }^{\circ} \mathrm{C}$ for $2 \mathrm{~h}$.

Phase formation has been conformed using PANalytical XRERT-PRO diffractometer. Particles size has been conformed by FEI make transmission electron microscopy (TEM). We have carried out a detailed magnetization, relaxation, and photomagnetic studies via a coupled optical fiber to a $\mathrm{Kr}^{+}$laser (multiline of $647.1-676.4 \mathrm{~nm}$ ) or to the cavity of a MPMS-55 Quantum Design superconducting quantum interference device magnetometer. ${ }^{7}$

\section{RESULTS AND DISCUSSIONS}

X-ray diffraction of the sample $\mathrm{Ni}_{0.5} \mathrm{Zn}_{0.5} \mathrm{Fe}_{1.7} \mathrm{Co}_{0.3} \mathrm{O}_{4}$ exhibits essentially a monophasic structure. A few very weak extra lines are due to $\alpha-\mathrm{Fe}_{2} \mathrm{O}_{3}$. Transmission electron micrograph (Fig. 1) exhibits variation of particle size and morphol-

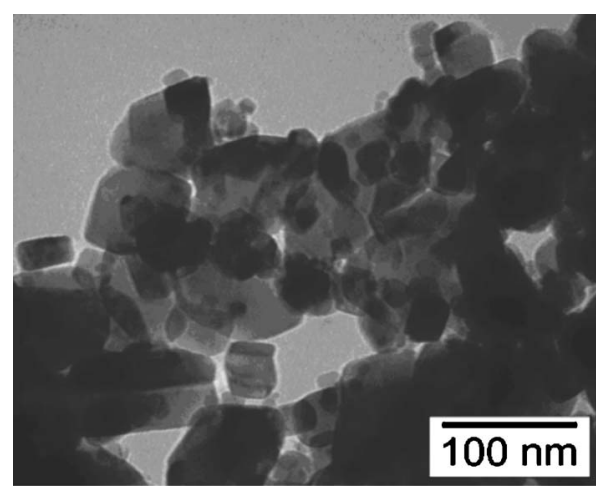

FIG. 1. TEM of $\mathrm{Ni}_{0.5} \mathrm{Zn}_{0.5} \mathrm{Fe}_{1.7} \mathrm{Co}_{0.3} \mathrm{O}_{4}$ nanocrystaline powder 


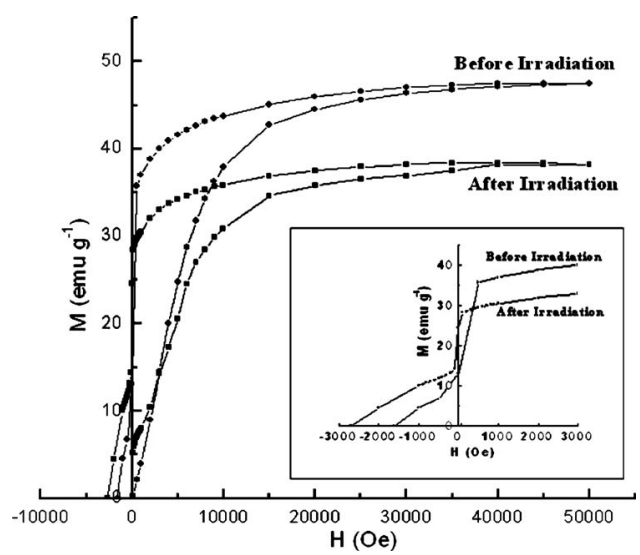

FIG. 2. Hysteresis loop on $\mathrm{Ni}_{0.5} \mathrm{Zn}_{0.5} \mathrm{Fe}_{1.7} \mathrm{Co}_{0.3} \mathrm{O}_{4}$ nanocrystaline powder.

ogy. While the particle size varies between 20 and $90 \mathrm{~nm}$, the morphology exhibits irregular shape as well as regular shape such as cuboid or square.

Figure 2 shows the hysteresis for the sample measured at $10 \mathrm{~K}$ up to a field of $5 \mathrm{~T}$ after the sample is zero field cooled from ambient before and after irradiation. The magnified demagnetization part is shown in the inset. A simultaneous observation of the absence of complete saturation as well as a large coercivity and remanance are indications of variation in particle size, which gets support from TEM data also suggesting a mixture of superparamagnetic and ferrimagnetic particles. The large coercivity of around 1600 Oe is essentially due to substitution of Co ions in the lattice, which introduces a large anisotropy in the spinel structure. This increases to 2700 Oe after irradiation. Similarly, $M_{r}$ (remanent magnetization) increases from 13 to $25 \mathrm{emu} / \mathrm{g}$ after irradiation. The specific magnetization value measured at $10 \mathrm{~K}$ and $5 \mathrm{~T}$ is $43 \mathrm{emu} / \mathrm{g}$ which is equivalent to $1.85 \mathrm{bohr}$ magneton/f.u. This reduced to $35 \mathrm{emu} / \mathrm{g}$ after the irradiation. These values are less compared to the bulk $\mathrm{Ni}_{0.5} \mathrm{Zn}_{0.5} \mathrm{Fe}_{2} \mathrm{O}_{4}$. The reduced magnetization in the nanocrystalline form is now well documented and it arises due to several reasons. Surface effects leading to noncolinearity of magnetic moments, swapping of sites, and weakening of superexchange interaction are among several reasons for the reduction of magnetic moments. ${ }^{8}$

Figure 3 shows the temperature dependence of magnetization in zero field cooled (ZFC) and field cooled (FC) con-

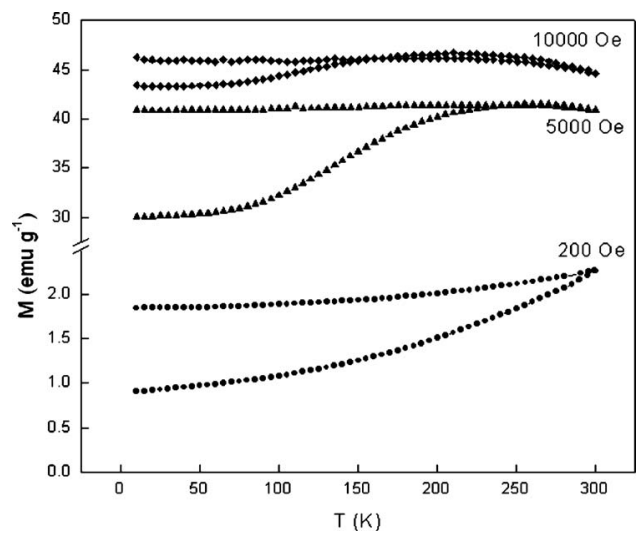

FIG. 3. ZFC and FC at 200, 5000, and 10000 Oe.

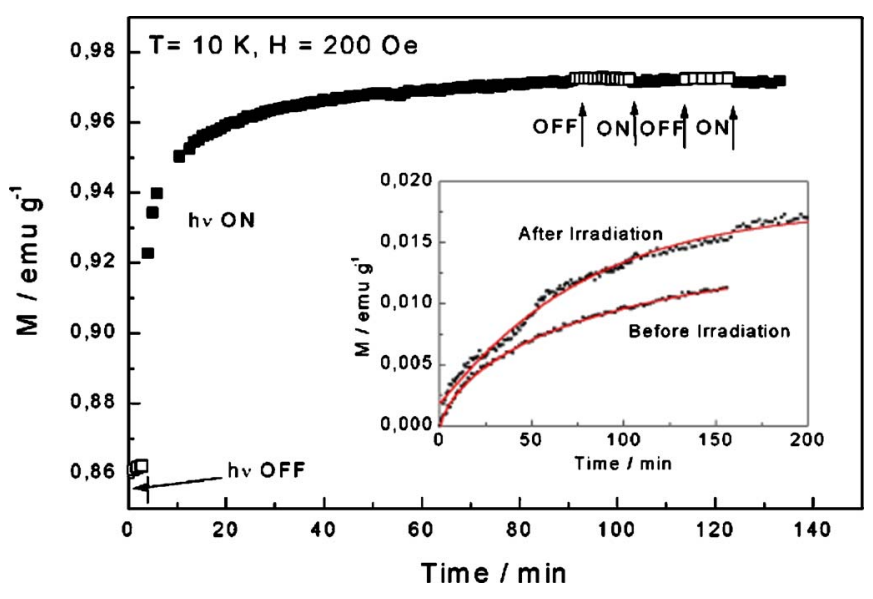

FIG. 4. $M$ vs time off and on condition. Inset: $M$ vs $T$ with and without irradiation in a field of 200 Oe (experimental points:square; liner fit:red line).

ditions measured at three different fields of 200, 5000, and 10000 Oe. A large bifurcation is seen between ZFC and FC data even up to a field of $10000 \mathrm{Oe}$. This is one of the characteristics of spin/cluster glass system and nanoparticles. However, spin glass, generally, exhibits a cusp and a sharp decrease in ZFC plot, characteristic of spin freezing temperature. The absence of such features would rather suggest a cluster glass type of behavior possibly originating from the nanosized structure. Some other noteworthy features of Fig. 3 are the shift of the bifurcation point to lower temperatures as the strength of the applied dc magnetic field increases. These are also characteristics of the cluster glass behavior. We carried out kinetic studies in a field of 200 Oe when the irradiation is switched on and off. A large rise of approximately $12 \%$ is seen in the initial $1800 \mathrm{~s}$ of irradiation, as shown in Fig. 4. This result is characteristic of the population of a magnetic state. Then, magnetization continues to rise with much smaller time dependence. At that point, when the light is switched off for a period of nearly $1 \mathrm{~h}$, no further change is noticed and further irradiation does not anymore affect the magnetic response. This kind of long relaxation is characteristic of metastable magnetic state. Interestingly, a similar observation has been made by Seki et al. while studying the photoinduced effects in the thin films of $\mathrm{Al}_{0.5} \mathrm{Fe}_{2.5} \mathrm{O}_{4}$ thin films. ${ }^{9}$ They attribute this behavior to the melting of the cluster glass state.

We further studied the evolution of the magnetization as a function of time, both in dark and after illumination at different temperatures. We show data obtained in the dark before and postirradiation at $200 \mathrm{Oe}$ and at $100 \mathrm{~K}$ in the inset of Fig. 4. An increase in the magnetization as a function of the time is clearly seen. We have carried out this measurement also at 50 and $150 \mathrm{~K}$ and similar results are obtained. We have fitted the data to an empirical stretched exponential, which has been commonly used to analyze this long time relaxation. ${ }^{10}$ Hence, the time evolution of the magnetization is analyzed using a combination of a stretched exponential and a constant term,

$$
M(t)=M_{0}-M_{r} \exp \left[-(t / \Gamma)^{\beta}\right] .
$$

Here, $\Gamma$ is the characteristic time constant, $M_{0}$ represents 
TABLE I. Fitting parameters for the evolution of magnetization with time in the dark and after irradiation at different temperatures $(H=200 \mathrm{Oe})$ from Eq. (1) (see text).

\begin{tabular}{|c|c|c|c|c|c|c|c|c|}
\hline \multirow[b]{2}{*}{$T / K$} & \multicolumn{2}{|c|}{$M_{0} / \mathrm{emu} \mathrm{g}^{-1}$} & \multicolumn{2}{|c|}{$M_{r} / \mathrm{emu} \mathrm{g}^{-1}$} & \multicolumn{2}{|c|}{$\beta$} & \multicolumn{2}{|c|}{$\Gamma / \min$} \\
\hline & Dark & $\begin{array}{c}\text { After } \\
\text { irradiation }\end{array}$ & Dark & $\begin{array}{c}\text { After } \\
\text { irradiation }\end{array}$ & Dark & $\begin{array}{c}\text { After } \\
\text { irradiation }\end{array}$ & Dark & $\begin{array}{c}\text { After } \\
\text { irradiation }\end{array}$ \\
\hline 50 & 0.9307 & 1.16841 & 0.0143 & 0.00464 & 0.5821 & 0.82728 & 92.35 & 45.39601 \\
\hline 100 & 1.0432 & 1.28025 & 0.0152 & 0.01656 & 0.6742 & 1.01027 & 93.40 & 76.36605 \\
\hline 150 & 1.2167 & 1.43687 & 0.0117 & 0.00894 & 0.6869 & 0.72278 & 68.92 & 34.78347 \\
\hline
\end{tabular}

an intrinsic ferromagnetic component, and $M_{r}$ is related to a glassy component contributing to the relaxation. The parameters derived from the above fit of the plots corresponding to the measurements at different temperatures are summarized in Table I.

Since the light irradiation has a significant influence on the magnetic behavior and also we observe large bifurcation of $\mathrm{FC}$ and $\mathrm{ZFC}$ data recorded at different fields, we considered it worthwhile to compare the FC and ZFC measurements in dark and after illumination. Figure 5 compares one such typical data recorded in a field of 200 Oe. It is noteworthy that while the FC data do not change on irradiation, the ZFC plot, however, exhibits significant enhancement in magnetization on irradiation at low temperatures up to about $100 \mathrm{~K}$. Similar results are reported for the spinel $\mathrm{Ni}_{0.7} \mathrm{Zn}_{0.3} \mathrm{Fe}_{1.7} \mathrm{Ti}_{0.3} \mathrm{O}_{4}$ by Seki et al. ${ }^{3}$ These authors also reported no such divergence in ZFC data with and without irradiation for $\mathrm{Ni}_{0.4} \mathrm{Zn}_{0.6} \mathrm{Fe}_{2} \mathrm{O}_{4}$. The same group has earlier reported photoinduced enhancement of magnetization for Tisubstituted $(\mathrm{Mg}, \mathrm{Fe})_{3} \mathrm{O}_{4}$ film. ${ }^{5}$ In both the cases, the enhancement in magnetization is attributed to $\mathrm{Ti}^{4+}$ ion, which undergoes photoinduced charge transfer with $\mathrm{Fe}^{2+}$ ions at $B$ site in the spinel structure. This behavior is an indication of the melting of the cluster glass state on light irradiation.

The distribution of cations in the bulk form may be represented as

$$
\left(\mathrm{Zn}_{0.5} \mathrm{Fe}_{0.5}\right)_{A}\left(\mathrm{Ni}_{0.5} \mathrm{Co}_{0.3} \mathrm{Fe}_{1.2}\right)_{B} \mathrm{O}_{4-\delta} .
$$

Assuming that $\mathrm{Fe}$ and Co exist only in 3+ state, whereas $\mathrm{Zn}$ and $\mathrm{Ni}$ exist in $2+$ state, which is also necessary for

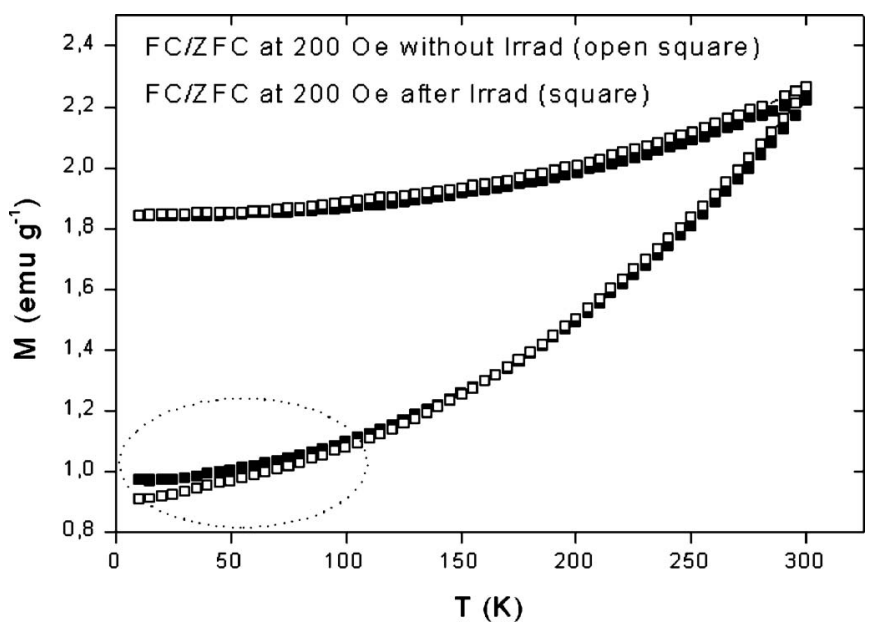

FIG. 5. ZFC and FC before and after irradiation in 200 Oe field. charge balance, if $\delta=0$. In practical situation, however, $\delta$ is often nonzero and therefore a trace amount of $\mathrm{Fe}^{2+}$ and $\mathrm{Co}^{2+}$ may also be expected in the compound, which eventually triggers charge transfer among $\mathrm{Co}$ and $\mathrm{Fe}$ ions. Besides the possibility of $\mathrm{Fe}$ and $\mathrm{Co}$ existing in the variable valence state, Co has additional degree of freedom and can exist in variable spin states. These variable valence and spin states, particularly, on photoirradiation, may exhibit interesting changes in the magnetic properties. For example, $\mathrm{Co}^{3+}$ in the low spin state with configuration $t_{2 g}^{6} e_{g}^{0}(S=0)$ is a diamagnetic, while the high spin state $t_{2 g}^{4} e_{g}^{2}(S=2)$ is paramagnetic.

We believe that IVCT, which may occur between cations at equivalent energy sites by photon irradiation, gives different valence states of cations and hence variation in properties. In addition, spin transition, which is seen on photoirradiation in cobalt containing oxides, also plays a significant role. $^{11}$.

We propose a core-shell type of structure due to large surface effects in nanoparticles. The surface spins, which are rather disordered, interact strongly with the core spins and may cause frustration giving cluster glass type of behavior. The extent of frustration and hence the size of the clusters depend on the different conditions of measurement such as temperature, field, and photoirradiation. The magnetic clusters may gradually reorient the freezing spins/melting of cluster glass as the measuring conditions vary. In addition, the charge transfer and spin transition also manifest themselves on the different magnetic and photomagnetic properties.

${ }^{1}$ H. Huhtinen, R. Laiho, E. Lähderanta, L. S. Vlasenko, M. P. Vlasenko, and V. S. Zakhvalinskii, Phys. Rev. B 62, 11614 (2000).

${ }^{2}$ M. Baran, S. L. Gnatchenko, O. Yu. Gorbenko, A. R. Kaul, R. Szymczak, and H. Szymczak, Phys. Rev. B 60, 9244 (1999).

${ }^{3}$ M. Seki, A. K. M. Akther Hossain, T. Kawai, and H. Tabata, J. Appl. Phys. 97, 083541 (2005)

${ }^{4}$ Y. Muraoka, H. Tabata, and T. Kawai, Solid State Commun. 120, 225 (2001).

${ }^{5}$ Y. Muraoka, H. Tabata, and T. Kawai, Appl. Phys. Lett. 76, 1179 (2000). ${ }^{6}$ S. Hayami, Z. Gu, M. Shiro, Y. Einaga, A. Fujishima, and O. Sato, J. Am. Chem. Soc. 122, 7126 (2000); C. Carbonera, A. Dei, C. Sangregorio, and J.-F. Letard, Chem. Phys. Lett. 396, 198 (2004).

${ }^{7}$ For more details see, for instance, J.-F. Létard, J. Mater. Chem. 16, 2550 (2006).

${ }^{8}$ R. H. Kodama, J. Magn. Magn. Mater. 200, 359 (1999).

${ }^{9}$ M. Seki, A. K. M. Akther Hossain, H. Tabata, and T. Kawai, Solid State Commun. 133, 791 (2005)

${ }^{10}$ S. Nakashima, K. Fujita, K. Tanaka, and K. Hirao, J. Phys.: Condens. Matter 17, 137 (2005).

${ }^{11}$ D. Bahadur, S. Asthana, C. Carbonera, C. Desplanches, and J.-F. Létard, Solid State Commun. 142, 132 (2007). 